\title{
The Implementation of Mental Contrasting in Romantic Relationship: A Review
}

\author{
Yitong Zhu \\ New York University, New York, USA \\ Email:yz7575@nyu.edu
}

How to cite this paper: Zhu, Y. T. (2022). The Implementation of Mental Contrasting in Romantic Relationship: A Review. Psychology, 13, 273-285.

https://doi.org/10.4236/psych.2022.132016

Received: January 14, 2022

Accepted: February 22, 2022

Published: February 25, 2022

Copyright (c) 2022 by author(s) and Scientific Research Publishing Inc. This work is licensed under the Creative Commons Attribution International License (CC BY 4.0).

http://creativecommons.org/licenses/by/4.0/

\begin{abstract}
Mental contrast is one of the self-regulation strategies. The contrast between the imagination of the desired goal and the reality of the obstacles motivates the individual to take effective action in the present to help achieve the goal. Mental contrast has been found to be effective in achieving goals in many aspects of life. This paper reviews the effectiveness of mental contrast in romantic relationship maintenance and conflict resolution. It addresses insecurity and reconciliation behaviors in romantic relationships and provides directions for future research.
\end{abstract}

\section{Keywords}

Mental Contrasting, Implementation Intention, Romantic Relationship, Reconciliation Behavior

\section{Introduction}

Fantasy Realization Theory (FRT), as the basis of mental contrast, involves individuals' expectations of the future. Expectations are the beliefs and the assessments of the likelihood of an event occurring in the future. It involves two types of fantasies, positive and negative, which arise from the individual's evaluation of the probability of positive and negative fantasies in the future (Oettingen, 2012). Mental contrast strategies are considered the way individuals maximize their goals by balancing positive and negative perceptions of the upcoming reality (Oettingen, 1999).

According to Oettingen (1999), individuals can work in four ways when achieving their future goals. Oettingen (1999) argues that by using only indulgent strategies (positive fantasies), individuals may ignore the adverse effects of the upcoming reality. This is because indulgence leads to avoidance and loss of motivation following any difficulties in achieving future goals. However, merely dwelling on 
the reality of the obstacles (negative fantasies) can lead to reality-related obstacles dampening the individual's enthusiasm to achieve the goal (Oettingen, 1999).

It has been shown that dwelling is better correlated with goal attainment than indulging (Oettingen \& Mayer, 2002), which may be due to the fact that compared to dwelling, indulging is overly idealistic in thinking about future goals and is more likely to produce fragile optimism. On the other hand, Dwelling takes more into account possible obstacles and prepares adequately for achieving goals (Oettingen \& Mayer, 2002). Meanwhile, an alternative strategy to mental contrasts is known as reverse contrasts, which implies reflecting on real obstacles before fantasizing about ideal futures and goals (Schrage et al., 2019). However, the reverse contrast strategy is to imagine the desired future after reflecting on the real obstacles, which leads to the inability of the individual to consider the reality obstacles as a hindrance to achieving the desired end. Thereby leading to a lack of intrinsic connection between the desired future and reality (Schrage et al., 2019).

In order to address the mindset mentioned above as a hindrance to individuals in pursuing their future goals, Oettingen (1999) proposed a new way of thinking, which is mental contrasting. Hence, the main purpose of this review is to outline the major milestones in the application of the mental contrast mindset in romantic relationships, the current burden of the mental contrast mindset in relationship regulation, and the technical applications of mental contrasting.

\section{Mental Contrasting}

To address the ineffective or negative effects of the above self-regulation strategies on goal attainment, Oettingen (1999) proposed mental contrast strategy. Mental contrast refers to the challenge of turning the fantasy of the desired future into reality (Oettingen, 2019), which is considered an effective strategy for overcoming challenges and achieving goals. It helps individuals look ahead to possible future plans by using free fantasies (indulging) while assisting individuals in thinking positively about realistic obstacles that prevent the achievement of desired future goals through negative fantasies (Oettingen, 2000, 2012, 2014).

In mental contrasts, people first begin to imagine a possible ideal future (e.g., individuals are happier in relationships when conflicts and contradictions are reconciled) and then reflect on realistic barriers that prevent goal implementation (e.g., difficulty controlling self-esteem to initiate reconciliation with others or controlling one's expression of negative emotions toward significant others; Oettingen, 2000, 2012, 2014, 2019).

In the mental contrasting strategy, realistic challenges are considered obstacles to achieving the goal. When individuals have high expectations of success, realistic obstacles are considered to be surmountable. Also, using the mental contrasting strategy helps individuals create a solid internal link between the expected future and the realistic obstacles (Kappes \& Oettingen, 2014; Kappes et al., 2012).

However, when realistic obstacles are perceived as insurmountable or indivi- 
duals have low expectations of their goals, the internal link between the desired future and realistic obstacles would have been weakening, which leads individuals to abandon the idea of pursuing their dreams (Oettingen, 2000, 2012, 2014; Oettingen et al., 2001; Houssais et al., 2012). In a nutshell, mental contrasts only reinforce individuals' pursuit of desired goals when individuals have higher expectations of achieving their goals (Schrage et al., 2019).

\subsection{Mental Contrasting and the Application of WOOP Strategies}

The strategy of mental contrasts is considered to have a prominent impact on goal achievement in different domains and with diverse populations (Schrage et al., 2019). Moreover, mental contrasts are deemed to be a spontaneous type of thinking. In response, Oettingen (2012) proposed using WOOP exercises to help individuals avoid cycles of indulgence and entanglement to further their desired goals (Oettingen, 2012; Gollwitzer, 1999).

According to research, WOOP involves four sequential steps, firstly, the identification and setting of the desired goal (wish), followed by identifying and imagining the outcome or self-feeling after achieving this goal (outcome); after that, the need to imagine the realistic obstacles in achieving this goal (obstacle); and finally, what actions we should use when the obstacles appear to overcome the obstacle (plan). Saddawi-Konefka et al. (2017) pointed out that using WOOP strategies in many different areas, for example, medical (Saddawi-Konefka et al., 2017), diet (Stadler et al., 2010), short-term training (Christiansen et al., 2010), etc., significantly improved goal attainment rates. Also, in WOOP practices, helping individuals create equally strong implicit connections between realistic barriers and desired actions so that when realistic barriers arise, individuals take action to overcome them (Kappes et al., 2012; Gollwitzer, 2014).

\subsection{Implementation of Mental Contrast in Romantic Relationships}

Although a large body of research supports the use of mental contrast in many domains, mental contrasting alone to develop goal intentions does not guarantee the success of subsequent actions (Wang et al., 2021). A clear picture of goals and realistic obstacles still requires planning for the following activities. Implementation intentions are actually if-then plans that help individuals plan specific behaviors to occur at particular times and places and guide individuals through specific steps to achieve the goal further (Gollwitzer, 1999; Sheeran \& Webb, 2004; Webb \& Sheeran, 2007). Through this approach, implementation intentions can help bridge the gap between goals and actions (Wang et al., 2021). Schrage et al. (2019) found that Mental Contrasting Implementation Intention (MCII) can minimize negative behaviors in intimate relationships and enhance communication in romantic relationships.

Even when individuals develop a strong commitment to goals through mental contrasting, they cannot always translate that commitment into action and successfully achieve their goals (Wang et al., 2021). For example, people may have 
difficulty implementing appropriate behaviors because of their ingrained habits and may forget to act in order to overcome realistic obstacles (Oettingen, 2012). Implementing intentions is a strategy to overcome these challenges because it further strengthens the link between realistic barriers and goal-achievement-related behaviors and overcomes the obstacles (Kappes et al., 2012). A large body of research shows that in personal goal pursuit, the combination of mental contrast and implementation intent leads to greater effectiveness (Adriaanse et al., 2010; Kirk et al., 2013).

The use of mental contrasting to resolve individuals' conflicts and problems in intimate relationships has become a new topic in academia. We aim to study the use of mental contrasting and the implementation of intention to regulate the emotional problems of both partners to maintain emotional stability based on the conflicts and contradictions that individuals encounter in intimate relationships (Houssais et al., 2012; Schrage et al., 2019; Wittleder et al., 2020). Moon (2017) proposed that individuals go through stages of disillusionment and introspection in intimate relationships. During the disillusionment and introspection phase, individuals can be filled with a lack of understanding and conflict because of the other person's behavior. Specifically, in the disillusionment stage, individuals experience a cycle of insecurity and thus misunderstand each other. For the introspective stage, individuals develop regrets about starting a relationship with their partners and reflecting on the barriers that existed in the relationship (Moon, 2017).

\subsection{Application of MCII to Insecure Behavior in Romantic Relationships}

In intimate relationships, insecure partners typically have higher attachment anxiety, lower self-esteem, and individuals at high risk for depression (Collins, 1996; De Cuyper et al., 2014; Joiner et al., 1999). In two studies on whether feelings of security moderated the relationship between attachment and relationship satisfaction, it was found that lower feelings of security negatively influenced individuals' satisfaction with intimate relationships and moderated the relationship between attachment and relationship satisfaction (Sadikaj et al., 2015; Roberts et al., 2014).

Hazan \& Shaver (1994) stand for a species survival perspective, arguing that attachment is a conservatively evolved behavioral system that helps organisms promote survival by establishing attachments with other organisms in the face of external or internal threats. Individuals judge whether to establish an attachment relationship with an attachment partner by measuring the availability, trustworthiness, and responsiveness to their needs (Sadikaj et al., 2015). When individuals have a high level of attachment security and believe that their attachment partner will support their responses accordingly, they show comfortable attachment and positive self-perceptions about intimate relationships. In contrast, insecure individuals tend to have higher levels of anxiety and avoidance, reflecting ongoing concerns about rejection, abandonment, and a strong desire for intimate at- 
tachment relationships (Davis et al., 2003).

Sadikaj et al. (2015) suggest that individuals' perceptions of safety in intimate relationships determine their patterns of being in intimate relationships and have a significant impact on the quality of romantic relationships. Although a large body of research has found that helping partners recall secure relationship experiences or subconsciously helping them increase their exposure to and perception of words and phrases related to "relationship" and "support" can help partners increase their sense of security and positive relationship perceptions (Rowe \& Carnelley, 2003; Carnelley \& Rowe, 2007), this approach relies on the allegedly distrustful partner and social support. However, individuals who are intrinsically insecure need to use other methods to help regulate their insecurities.

Another approach is to enhance the individual's sense of security in the intimate relationship by helping the individual to exercise self-affirmation and by using cognitive reassessment strategies to help the individual regain confidence and eliminate their negative perceptions of their partner's behavior and attitudes (Marigold et al., 2010). In a study by Stinson et al. (2011), self-affirmation interventions improved individuals' insecurities.

In contrast, a study that used Mental Contrasting Implementation Intention (MCII) to help individuals improve their insecurity in intimate relationships found that those in the MCII strategy group reported significant reductions in behaviors that targeted insecurity after one week and a substantial increase in their commitment in intimate relationships two months after the intervention. The MCII group reported significant reductions in insecurity-specific behaviors after one week and significant increases in commitment in intimate relationships two months after the intervention (Houssais et al., 2012). In Houssais et al. (2012), they compared the MCII, reverse contracting strategy, and unconditional control conditions to examine the effectiveness of different strategies in increasing individuals' insecurity in intimate relationships. The content of the reverse contracting strategy was consistent with MCII but in reverse order. Individuals need to measure realistic obstacles before engaging in positive fantasies about future goals.

The researchers randomly assigned the participants to different conditions (MCII, reverse contrasting strategy condition, and no strategy condition). The frequency of participants' behavioral insecurities and changes in relationship commitment before and after the experiment were compared through a week-long self-report questionnaire (Houssais et al., 2012). The main effects predicted by the conditions revealed a significant post-experimental decrease in insecure behaviors for participants in the MCII condition compared to the reverse contrasting condition and the control condition $(M=-1.63, S E=0.27, M=-0.78, S E=0.27, t$ $(113)=2.19, p=0.03 ; M=-0.82, S E=0.28, t(113)=2.07, p=0.04)$. However, no significant differences were found between participants in the reverse control and control groups ( $p>0.90$; Houssais et al., 2012).

This suggests that learning and using MCII strategies can effectively improve 
individuals' insecurities in intimate relationships. MCII strategies help individuals identify the insecure behaviors they want to improve in their intimate relationships and create expectations and confidence in reducing insecure behaviors, as well as help them think about the reality of their current obstacles (e.g., trusting their partner when they express praise for themselves, reducing the number of arguments number of times). In addition to this, the MCII strategy helps partners create an If-then plan to help individuals act quickly in the face of obstacles (implementation intention building; what to do if obstacles arise).

Also, Houssais et al. (2012) examined the effect of MCII strategies on caring commitment. Comparing the participants' reported relationship commitment two months earlier with the change in relationship commitment after using the strategy found that the participants in the MCII condition felt more committed to the current romantic relationship while their commitment to the relationship was significantly enhanced.

This study found that using MCII strategies to regulate insecurity from a self-regulatory perspective is essential for people to manage their insecurities. According to Davis et al. (2003), insecurity was found in individuals with avoidant attachment relationships and high anxiety. However, the participants in this study were not defined as individuals with high anxiety or avoidance, thus ignoring the lack of security experienced by a small group of people in intimate relationships. We believe that follow-up research is needed to examine insecurity in those with high anxiety and avoidant attachment relationships.

\subsection{Mental Contrasting in Reconciliatory Behavior in Intimacy Relationships}

Interpersonal offense in relationships is an inevitable part of our daily lives (Exline et al., 2011). Individuals can hurt each other, intentionally or unintentionally, by offending each other. And when people become aware of the disintegration of relationships caused by interpersonal conflict, they are faced with at least two challenging tasks. One is to resolve their negative emotions, which involves a process of self-forgiveness (Hall \& Fincham, 2005; Tangney et al., 2005; Hill et al., 2015). Another critical challenge is the adoption of restorative behaviors, which the perpetrator takes to repair the damage to personal relationships in situations where they have hurt others. Restorative behaviors include awareness, apologizing, seeking forgiveness, and attempting to reconcile (Exline et al., 2011; Oettingen, 2002; Oettingen et al., 2001; Sevincer \& Oettingen, 2013; Schrage et al., 2019).

\section{Reconciliation Behavior}

The act of reconciliation is an effective method of restoring the relationship after an interpersonal crime, which aims to repair the damage to the relationship after an interpersonal crime (Exline et al., 2011; Hannon et al., 2010). The interrelationship between forgiveness seeking and forgiveness based therein is referred to as the apology-forgiveness cycle (Hewitt \& Tavuchis, 1992). The reconciliatory 
behavior of the perpetrator is one of the most essential factors in this cycle (Bono et al., 2007). Reconciliation consists of various forms, including an apology (Exline et al., 2007), acknowledgment of wrongdoing (Eaton et al., 2006), demand for forgiveness (Witvliet et al., 2002), and provision of compensation (Witvliet et al., 2008).

Despite the many benefits of reconciliation, perpetrators may avoid effective reconciliation because they are unable to focus on overcoming their internal barriers. For example, perpetrators view apologizing as a demeaning act of self-worth (Kearns \& Fincham, 2005) and may face the possibility of rejection (Exline et al., 2007). In addition, the conduct of reconciliation does not guarantee the understanding of the victim (Schrage et al., 2019).

Schrage (2014) divides interpersonal aggression into internal and external, where internal refers to the inability to perform or the successful response after performing the reconciliation act due to the internal barriers of the individual. In comparison, external refers to the inability to understand due to the realistic obstacles in the victim. Thus, the success of the act of reconciliation does not depend solely on the reconciliation behavior of the perpetrator. Ignoring external barriers, the success of reconciliation also relies on the individual's sincerity in the apology (Smith, 2008). Therefore, using effective methods to help perpetrators develop illusions and confidence in successful binary relationship repair while helping individuals identify and work through realistic barriers is the key to reconciliation.

\section{Mental Contrasting and Conciliatory Behavior}

Regardless of the form and type of reconciliation approach used, the element they share contains their perception of the other person's victimization. Meanwhile, Baumeister et al. (1990) suggested that individuals experience negative emotions of remorse and sadness when accepting that they have been offended interpersonally. Also, feelings of remorse have been suggested to be useful as indicators of hurting others (Fisher \& Exline, 2006). Schrage et al. (2019) used guilt and sadness as emotional manipulation conditions in their study on the role of mental contrasting in reconciliation behavior and found that guilt emotions can contribute to individuals' subsequent perceptions of perceived motivational value (the importance of repairing the interpersonal offense to the perpetrator), expectations of future goals, and reconciliation goal commitment was significantly related. Thus, the key to implementing reconciliation behavior is to lead the perpetrator to realize their past mistakes and to develop feelings of guilt toward the victim.

As the result, guilt was highly correlated with motivational value, future expectations, and goal commitment (Schrage, 2014). This means that perpetrators are more likely to feel the importance of repairing the relationship, the illusion of expectation for the repaired relationship, and the confidence in the repaired relationship after they have developed a sense of guilt, where goal commitment 
was highly correlated with sincerity of subsequent reconciliation behavior and the quality of the reconciliation letter. In addition, only perpetrators who used mental contrasting strategies engaged in reasonable reconciliation behaviors (Schrage, 2014). This finding was replicated and certified in the study of Schrage et al. (2019) study. That is, mental contrasting has a significant effect on resolving interpersonal aggression than reverse contrasting strategy.

Meanwhile, in Schrage's (2014) study, experimenters compared the role of mental contrasting in perpetrators' perceived perpetrator barriers (internal) as well as victims' (external) barriers. The study showed that mental contrasting strategies based on goal expectation and goal pursuit (goal commitment) were more useful for perpetrators who perceived realistic barriers to exist in themselves (perpetrators themselves felt that committing the act of reconciliation would affect their self-esteem and self-image) than for those who perceived realistic barriers to exist in the victim (perpetrators were afraid or believed that even if they apologized the other person would not accept forgiveness) was more useful.

The above results show that perpetrators are more likely to assess their barriers and expectations of success. They also have the power to practice reconciliatory behaviors in accordance with their expectations of success (Schrage, 2014). Whereas, when barriers exist to the victim and other external conditions, it is difficult for perpetrators to assess the likelihood of success and the feasibility of the reconciliation behavior.

Subsidiarily, Schrage et al. (2019) examined whether spontaneous mental contrasting versus other strategies (indulging, dwelling, and reverse contrasting) had more substantial future expectations and settlement commitment. It also examined whether the expectation of success influenced the timeliness of participants' commitments to reconciliation behavior. Results found that spontaneous mental contrasting strategies predicted wise reconciliation behavior (Schrage, 2014). In addition, perpetrators of mental contrasting compared to other modes of thinking reported that compare with reconcile expectancy-dependent commitment behavior, the immediate expectation of reconciliation behavior is more dependent.

Alternatively, perpetrators who use mental contrasting strategies have extremely high expectations of success and develop a solid commitment to immediately reconcile and perform conciliatory behavior (Schrage et al., 2019). In contrast, perpetrators with lower expectations of success also have a weaker commitment to settle and delay or do not perform settlement behaviors.

Furthermore, research has found that for participants in the mental contrasting condition, expectancy-dependent immediacy of conciliatory behavior is highly correlated with settlement success (Schrage et al., 2019). In other words, it is when individuals who have more expectations of success and engage in conciliatory behavior quickly are more likely to reconcile with the victim successfully. For other thinking patterns, this predictive relationship was not evident. This study suggests that mental contrasting has high effectiveness in repairing interpersonal aggres- 
sion (Schrage et al., 2019). It also showed the effectiveness of mental contrasting in pursuing a desirable future in interpersonal relationships.

Schrage et al. (2019) investigated the reconciliation behavior of individuals in romantic relationships in both mental contrasting and indulging states in a laboratory setting. The researchers recruited 51 couples who remained in a romantic relationship for at least one year and lived together. They were asked to review violations that occurred within four months and were resolved during the experiment. They recorded their reconciliation behaviors in the laboratory by video recording and reported their reconciliation behaviors separately within two weeks of the experiment.

At the end of the video recording, they asked the victim and perpetrator to rate each other's and their reconciliation behaviors in the lab recordings based on the video recording and to rate their reconciliation behaviors on a multivariate scale by a third-party experimental researcher. The success of each party's reconciliation with the other and with themselves has collected again two weeks later.

Due to the previous study, the use of mental contrasting strategies by the perpetrators led the perpetrators to choose wise reconciliation behaviors and also affected the success of reconciliation. Also, perpetrators using more settlement behaviors after using mental contrasting predicted higher settlement reported by both parties after they had a discussion and two weeks after the experiment (Schrage et al., 2019). This suggests that regardless of the victim's expectation of successful reconciliation between the parties, the wise reconciliation behavior exhibited by the perpetrator is the key to a successful reconciliation.

Furthermore, Schrage et al. (2019) used the perpetrator's settlement behavior to mediate between the perpetrator's expectation of success and settlement. Also and used different strategies (MC/indulging) as a moderating variable between the perpetrator's target expectation and settlement behavior. By examining the model, the moderating behavior of Mental contrasting between goal expectation and reconciliation behavior was significant (Schrage et al., 2019). Also, the perpetrator's reconciliation behavior is substantial for the success of reconciliation. However, there was no significant effect of settlement behavior per se on settlement success for participants in the indulging condition. In addition, the model found that the higher the perpetrator's expectation of success triggered more settlement behavior (see Schrage et al., 2019). This result is consistent with the other path model.

Thus, both path models found that even in the laboratory and real-life self-reports for romantic relationships, higher perpetrator expectations of success in the mental contrasting condition mediated perpetrators' reconciliation behaviors and thus had an indirect effect on the success of reconciliation between them (Schrage et al., 2019). However, this effect was not significant for participants in the Indulging condition. 


\section{Limitations and Future Directions}

Nonetheless, due to the small sample size covered by the above studies in romantic relationships, we suggest that future research could begin by expanding the sample size and multi-age division of such romantic relationships. In addition, the interpersonal aggression reported was predominantly less severe (e.g., good attention lies and flirting with third parties) and did not involve brutal aggression. However, does it also involve reconciliatory behavior for more severe interpersonal aggressions (deception, violence, etc.)? Also, the need for victims to reconcile with their abusers is the focus of subsequent research.

Moreover, in future studies, attention to the diversity of experimental sites is still needed. In the studies by Schrage et al. (2019) and Schrage (2014), the settlement sites involved were in the laboratory environment. However, when participants are in a laboratory setting, they may control their behavior and adopt reconciliation behaviors recognized by the general public to present to the researchers to maintain their self-image. Therefore, studies involving reconciliation behaviors in everyday settings can be considered.

Beyond this, mental contrasting has been studied in a minimal number of relationships. The types of relationships involved are usually studies of romantic relationships and individual-work relationships as well. In more scenarios, the application of mental contrasting in family relationships and more complex intimate relationships and reconciliation behaviors has been neglected. Because of this, future research can focus on diverse relationships for more profound studies and explorations.

\section{Conflicts of Interest}

The author declares no conflicts of interest regarding the publication of this paper.

\section{References}

Adriaanse, M. A., Oettingen, G., Gollwitzer, P. M., Hennes, E. P., de Ridder, D. T., \& de Wit, J. B. (2010). When Planning Is Not Enough: Fighting Unhealthy Snacking Habits by Mental Contrasting with Implementation Intentions (MCII). European Journal of Social Psychology, 40, 1277-1293. https://doi.org/10.1002/ejsp.730

Baumeister, R. F., Stillwell, A., \& Wotman, S. R. (1990). Victim and Perpetrator Accounts of Interpersonal Conflict: Autobiographical Narratives about Anger. Journal of Personality and Social Psychology, 59, 994-1005. https://doi.org/10.1037/0022-3514.59.5.994

Bono, G., McCullough, M. E., \& Root, L. M. (2007). Forgiveness, Feeling Connected to Others, and Well-Being: Two Longitudinal Studies. Personality and Social Psychology Bulletin, 34, 182-195. https://doi.org/10.1177/0146167207310025

Carnelley, K. B., \& Rowe, A. C. (2007). Repeated Priming of Attachment Security Influences Later Views of Self and Relationships. Personal Relationships, 14, 307-320. https://doi.org/10.1111/j.1475-6811.2007.00156.x

Christiansen, S., Oettingen, G., Dahme, B., \& Klinger, R. (2010). A Short Goal-Pursuit Intervention to Improve Physical Capacity: A Randomized Clinical Trial in Chronic Back 
Pain Patients. Pain, 149, 444-452. https://doi.org/10.1016/j.pain.2009.12.015

Collins, N. L. (1996). Working Models of Attachment: Implications for Explanation, Emotion, and Behavior. Journal of Personality and Social Psychology, 71, 810-832. https://doi.org/10.1037/0022-3514.71.4.810

Davis, D., Shaver, P. R., \& Vernon, M. L. (2003). Physical, Emotional, and Behavioral Reactions to Breaking up: The Roles of Gender, Age, Emotional Involvement, and Attachment Style. Personality and Social Psychology Bulletin, 29, 871-884. https://doi.org/10.1177/0146167203029007006

De Cuyper, N., Sulea, C., Philippaers, K., Fischmann, G., Iliescu, D., \& De Witte, H. (2014). Perceived Employability and Performance: Moderation by Felt Job Insecurity. Personnel Review, 43, 536-552. https://doi.org/10.1108/pr-03-2013-0050

Eaton, J., Struthers, C. W., \& Santelli, A. G. (2006). Dispositional and State Forgiveness: The Role of Self-Esteem, Need for Structure, and Narcissism. Personality and Individual Differences, 41, 371-380. https://doi.org/10.1016/j.paid.2006.02.005

Exline, J. J., Deshea, L., \& Holeman, V. T. (2007). Is Apology Worth the Risk? Predictors, Outcomes, and Ways to Avoid Regret. Journal of Social and Clinical Psychology, 26, 479504. https://doi.org/10.1521/jscp.2007.26.4.479

Exline, J. J., Root, B. L., Yadavalli, S., Martin, A. M., \& Fisher, M. L. (2011). Reparative Behaviors and Self-Forgiveness: Effects of a Laboratory-Based Exercise. Self and Identity, 10, 101-126. https://doi.org/10.1080/15298861003669565

Fisher, M. L., \& Exline, J. J. (2006). Self-Forgiveness versus Excusing: The Roles of Remorse, Effort, and Acceptance of Responsibility. Self and Identity, 5, 127-146. https://doi.org/10.1080/15298860600586123

Gollwitzer, P. M. (1999). Implementation Intentions: Strong Effects of Simple Plans. American Psychologist, 54, 493-503. https://doi.org/10.1037/0003-066x.54.7.493

Gollwitzer, P. M. (2014). Weakness of the Will: Is a Quick Fix Possible? Motivation and Emotion, 38, 305-322. https://doi.org/10.1007/s11031-014-9416-3

Hall, J. H., \& Fincham, F. D. (2005). Self-Forgiveness: The Stepchild of Forgiveness Research. Journal of Social and Clinical Psychology, 24, 621-637. https://doi.org/10.1521/jscp.2005.24.5.621

Hannon, M., Gimpel, J., Tran, M., Rasala, B., \& Mayfield, S. (2010). Biofuels from Algae: Challenges and Potential. Biofuels, 1, 763-784. https://doi.org/10.4155/bfs.10.44

Hazan, C., \& Shaver, P. R. (1994). Deeper into Attachment Theory. Psychological Inquiry, 5, 68-79. https://doi.org/10.1207/s15327965pli0501_15

Hewitt, J. P., \& Tavuchis, N. (1992). Mea Culpa: A Sociology of Apology and Reconciliation. Stanford University Press.

Hill, P. L., Heffernan, M. E., \& Allemand, M. (2015). Forgiveness and Subjective Well-Being: Discussing Mechanisms, Contexts, and Rationales. In L. Toussaint, E. Worthington, \& D. Williams (Eds.), Forgiveness and Health (pp. 155-169). Springer.

https://doi.org/10.1007/978-94-017-9993-5_11

Houssais, S., Oettingen, G., \& Mayer, D. (2012). Using Mental Contrasting with Implementation Intentions to Self-Regulate Insecurity-Based Behaviors in Relationships. Motivation and Emotion, 37, 224-233. https://doi.org/10.1007/s11031-012-9307-4

Joiner, T. E., Metalsky, G. I., Katz, J., \& Beach, S. R. (1999). Depression and Excessive Reassurance-Seeking. Psychological Inquiry, 10, 269-278.

https://doi.org/10.1207/s15327965pli1004_1

Kappes, A., \& Oettingen, G. (2014). The Emergence of Goal Pursuit: Mental Contrasting Connects Future and Reality. Journal of Experimental Social Psychology, 54, 25-39. 
https://doi.org/10.1016/i.jesp.2014.03.014

Kappes, A., Singmann, H., \& Oettingen, G. (2012). Mental Contrasting Instigates goal Pursuit by Linking Obstacles of Reality with Instrumental Behavior. Journal of Experimental Social Psychology, 48, 811-818. https://doi.org/10.1016/j.jesp.2012.02.002

Kappes, M. S., Keiler, M., von Elverfeldt, K., \& Glade, T. (2012). Challenges of Analyzing Multi-Hazard Risk: A Review. Natural Hazards, 64, 1925-1958.

https://doi.org/10.1007/s11069-012-0294-2

Kearns, J. N., \& Fincham, F. D. (2005). Victim and Perpetrator Accounts of Interpersonal Transgressions: Self-Serving or Relationship-Serving Biases? Personality and Social Psychology Bulletin, 31, 321-333. https://doi.org/10.1177/0146167204271594

Kirk, D., Oettingen, G., \& Gollwitzer, P. M. (2013). Promoting Integrative Bargaining: Mental Contrasting with Implementation Intentions. International Journal of Conflict Management, 24, 148-165. https://doi.org/10.1108/10444061311316771

Marigold, D. C., Holmes, J. G., \& Ross, M. (2010). Fostering Relationship Resilience: An Intervention for Low Self-Esteem Individuals. Journal of Experimental Social Psychology, 46, 624-630. https://doi.org/10.1016/j.jesp.2010.02.011

Moon, C. (2017). Relationship-Bridge to the Soul. Vision Mountain Training Inc.

Oettingen, G. (1999). Free Fantasies about the Future and the Emergence of Developmental Goals. In J. Brandtstädter, \& R. M. Lerner (Eds.), Action \& Self-Development: Theory and Research through the Life Span (pp. 315-342). SAGE Publications, Inc. https://doi.org/10.4135/9781452204802.n11

Oettingen, G. (2000). Expectancy Effects on Behavior Depend on Self-Regulatory Thought. Social Cognition, 18, 101-129. https://doi.org/10.1521/soco.2000.18.2.101

Oettingen, G. (2012). Future Thought and Behaviour Change. European Review of Social Psychology, 23, 1-63. https://doi.org/10.1080/10463283.2011.643698

Oettingen, G. (2014). Rethinking Positive Thinking: Inside the New Science of Motivation. Current Publishing.

Oettingen, G. (2019). Locke and Latham's Legacy Provides a Model of Courage. Motivation Science, 5, 108-109. https://doi.org/10.1037/mot0000131

Oettingen, G., \& Mayer, D. (2002). The Motivating Function of Thinking about the Future: Expectations versus Fantasies. Journal of Personality and Social Psychology, 83, 11981212. https://doi.org/10.1037/0022-3514.83.5.1198

Oettingen, G., Pak, H. J., \& Schnetter, K. (2001). Self-Regulation of Goal-Setting: Turning Free Fantasies about the Future into Binding Goals. Journal of Personality and Social Psychology, 80, 736-753. https://doi.org/10.1037/0022-3514.80.5.736

Roberts, S. C., Little, A. C., Burriss, R. P., Cobey, K. D., Klapilová, K., Havlíček, J., Jones, B. C., DeBruine, L., \& Petrie, M. (2014). Partner Choice, Relationship Satisfaction, and Oral Contraception. Psychological Science, 25, 1497-1503. https://doi.org/10.1177/0956797614532295

Rowe, A., \& Carnelley, K. B. (2003). Attachment Style Differences in the Processing of Attachment-Relevant Information: Primed-Style Effects on Recall, Interpersonal Expectations, and Affect. Personal Relationships, 10, 59-75. https://doi.org/10.1111/1475-6811.00036

Saddawi-Konefka, D., Baker, K., Guarino, A., Burns, S. M., Oettingen, G., Gollwitzer, P. M., \& Charnin, J. E. (2017). Changing Resident Physician Studying Behaviors: A Randomized, Comparative Effectiveness Trial of Goal Setting versus Use of WOOP. Journal of Graduate Medical Education, 9, 451-457.

https://doi.org/10.4300/jgme-d-16-00703.1

Sadikaj, G., Moskowitz, D. S., \& Zuroff, D. C. (2015). Felt Security in Daily Interactions as 
a Mediator of the Effect of Attachment on Relationship Satisfaction: Some of the Results Reported in This Article Were Previously Presented at the Annual Meeting of the Society for Interpersonal Theory and Research in Montreal, Canada (May 2012). European Journal of Personality, 29, 187-200. https://doi.org/10.1002/per.1988

Schrage, J. (2014). Mental Contrasting and Conciliatory Behavior in Perpetrators. Doctoral Dissertation, Staats-und Universitätsbibliothek Hamburg Carl von Ossietzky.

Schrage, J., Schwörer, B., Krott, N. R., \& Oettingen, G. (2019). Mental Contrasting and Conciliatory Behavior in Romantic Relationships. Motivation and Emotion, 44, 356-372. https://doi.org/10.1007/s11031-019-09791-9

Sevincer, A. T., \& Oettingen, G. (2013). Spontaneous Mental Contrasting and Selective Goal Pursuit. Personality and Social Psychology Bulletin, 39, 1240-1254. https://doi.org/10.1177/0146167213492428

Smith, T. (2008). The Letter, the Spirit, and the Future: Rudd's Apology to Australia's Indigenous people. Australian Review of Public Affairs.

http://www.australianreview.net/digest/2008/03/smith.html

Stadler, G., Oettingen, G., \& Gollwitzer, P. M. (2010). Intervention Effects of Information and Self-Regulation on Eating Fruits and Vegetables over Two Years. Health Psychology, 29, 274-283. https://doi.org/10.1037/a0018644

Stinson, D. A., Logel, C., Shepherd, S., \& Zanna, M. P. (2011). Rewriting the Self-Fulfilling Prophecy of Social Rejection. Psychological Science, 22, 1145-1149. https://doi.org/10.1177/0956797611417725

Tangney, J. P., Boone, A. L., \& Dearing, R. (2005). Handbook of Forgiveness. Routledge.

Wang, G. X., Wang, Y., \& Gai, X. S. (2021). A Meta-Analysis of the Effects of Mental Contrasting with Implementation Intentions on Goal Attainment. Frontiers in Psychology, 12, Article ID: 565202. https://doi.org/10.3389/fpsyg.2021.565202

Webb, T. L., \& Sheeran, P. (2004). Identifying Good Opportunities to Act: Implementation Intentions and Cue Discrimination. European Journal of Social Psychology, 34, 407419. https://doi.org/10.1002/ejsp.205

Webb, T. L., \& Sheeran, P. (2007). How Do Implementation Intentions Promote Goal Attainment? A Test of Component Processes. Journal of Experimental Social Psychology, 43, 295-302. https://doi.org/10.1016/j.jesp.2006.02.001

Wittleder, S., Kappes, A., Krott, N. R., Jay, M., \& Oettingen, G. (2020). Mental Contrasting Spurs Energy by Changing Implicit Evaluations of Obstacles. Motivation Science, 6, 133155. https://doi.org/10.1037/mot0000140

Witvliet, C. V., Worthington, E. L., Root, L. M., Sato, A. F., Ludwig, T. E., \& Exline, J. J. (2008). Retributive Justice, Restorative Justice, and Forgiveness: An Experimental Psychophysiology Analysis. Journal of Experimental Social Psychology, 44, 10-25. https://doi.org/10.1016/j.jesp.2007.01.009

Witvliet, C., Ludwig, T., \& Bauer, D. J. (2002). Please Forgive Me: Transgressors' Emotions and Physiology during Imagery of Seeking Forgiveness and Victim Responses. Journal of Psychology and Christianity, 21, 219-233. 